\title{
Young women with breast cancer-using the healing tool; writing blogs
}

\author{
Octavio Muniz da Costa Vargens ${ }^{1}$ and Carina M. Berterö ${ }^{2}$ \\ ${ }^{1}$ Faculty of Nursing, Rio de Janeiro State University, Rio de Janeiro, Brazil \\ ${ }^{2}$ Division of Nursing Science, Department of Medical and Health Sciences, Linköping University, Linköping, Sweden
}

\begin{abstract}
Purpose: This qualitative study aims to interpret and describe how young women diagnosed with a breast cancer uses blogs to manage daily life.

Methods: 14 blogs written by women diagnosed with breast cancer aged between 25 and 38 years. These blogs were analysed using qualitative thematic analysis.

Results: Four themes were identified in the data body illustrating what the women were writing about in their blogs: Experiencing frustration, The fear is bigger than death, Preparing for physical changes, Body and mind are in disharmony. These four themes ended up in a concluding theme: The healing effect of writing a blog.

Conclusion: The young women used writing blogs as a healing activity. The writing was a channel for emotions and thoughts, but was also a way of sharing experiences and supporting each other. Their narratives revealed the impact of breast cancer experiences on their personal, familial and social lives. Reading blogs is an activity that could allow healthcare professionals to better understand these women's life situation and needs.

Implications for practice: Blogs could become a useful tool for healthcare professionals, relatives, patients and the people around them. By reading blogs, not necessarily commenting on or writing them, there will be a better and deeper understanding about the effects of a cancer diagnosis. Using blogs could facilitate the provision of requested and needed health care activities.
\end{abstract}

\section{Introduction}

The risk of breast cancer increases with age; it is most common after the age of 50, but reports have been published showing an increase in the incidence and mortality in young women i.e., $<40$ years of age $[1,2]$. Breast cancer is the leading cause of death in both developed and developing countries [2]. Approximately, 5\% to 7\% are young women in some statistic series [3]. Although a diagnosis of breast cancer is distressing at any age, this occurrence in young women brings several unique challenges and problems related to issues such as fertility, premature menopause, sexual functioning, breast cancer during pregnancy or postpartum $[4,5]$. These problems are also related to psychosocial matters such as career and work and uncertainty about disease relapse $[4,6,7]$. It could be concluded that younger women have greater symptom burden and negative long-term psychosocial and socioeconomic problems and poorer quality of life (QOL) after breast cancer diagnosis and treatment than older women [8].

These women need social support and networks to share personal stories and experiences but also to discuss disease issues, broaden their cancer-knowledge and validate information received from health care professionals [9]. This social support could be found within writing personal blogs about their breast cancer experience. Blogging activities could be seen as an online health resource and can promote good health. There are studies on the positive effect of expressive writing, online support as blogging, reported in psychological and oncology social work $[10,11]$. Hence, blogging is a way for young women with breast cancer to express themselves. The purpose of this qualitative, exploratory study was to interpret and describe how women diagnosed with a breast cancer uses blogs to manage daily life.

\section{Method}

This qualitative, exploratory study used Thematic Analysis (TA) according to Braun and Clark [12], which allows researchers to analyse and report patterns and themes within data

\section{Study participants}

A purposive strategy was used. Definitions vary regarding the age range associated with cancer in young adults [13], but the focus of this study was on those women aged 20-39 years at diagnosis and treatment. This study focuses on blogs written in Swedish and the sampling criteria were as follows: the blog had to be publicly accessible with no login in or password required; all blogs should focus on the breast cancer experiences; it had to be clearly stated or noted directly or indirectly, that the woman had received her breast cancer diagnosis before the age of 40; the blog had to be easily found on the web using the search terms, 'young women with breast cancer' AND 'blogs'; and finally, the blog had to be presented in such a way that its content provided statements that could be analysed and interpreted according to the aim of the study. The feedback quite frequently posted were not included in the analysis. A total of 14 blogs were identified regarding the inclusion criteria, and those were included for analysis. The women were aged between 25

Correspondence to: Carina M. Berterö, $\mathrm{PhD}$, Professor, Division of Nursing Science, Department of Medical and Health Sciences, Faculty of Health Sciences, Linköping University, Linköping, Sweden, E-mail: carina.bertero@liu.se

Key words: breast cancer, young women, blogs, thematic analysis

Received: July 19, 2017; Accepted: August 02, 2017; Published: August 06, 2017 
and 38 years (median 30 years), when diagnosed with breast cancer. Seven out of the 14 women had children. (About half of the women had passed away. This was noted in the blogs)

\section{Data collection and analysis}

Ethical considerations are evolving due to the expanding data corpus on the internet. Therefor the researchers carefully considered the ethical issues of privacy, confidentiality and other ethical principles before and throughout the study. It was shown that bloggers make conscious privacy choices that researchers then must discern and respect. Those blogs that are identified via search engines and open to responses from others are clearly public blogs. Ethical approval was obtained from the Regional Ethical Review Board, who demanded special concerns about the women's' confidentiality. No statements are provided since it is easy to recognize and find the women on the internet.

Data extracted from the blogs were inserted in a particular file for analysis. The text was organized in chronological order, from diagnosis until the most recent post message. The data body comprised about 4,10,000 words, and were analysed by using TA [12], following the six phases:

1) Familiarizing yourself with data; data was read and re-read several times to gain familiarity.

2) Generating initial codes; codes were identified and assigned to text segments that conveyed interesting information considered pertinent to the research question and the aim.

3) Searching for themes; all initial codes relevant to the research question were incorporated into a theme. These initial codes could be combinations of different codes that may have been very similar or may have been considered to concern the same aspect of the phenomenon.

4) Reviewing themes; the themes that emerged from each blog were compared and contrasted, resulting in the identification of themes that were common across all blogs.

5) Defining and naming themes; once a coherent pattern was formed the themes were considered in relation to the data set as a whole. The themes were named according to their content.

6) Producing the report; presenting the themes and illustrating them [12]. In order to increase the trustworthiness of the findings, the analysis was subjected to peer debriefing by the researchers and agreement was reached.

\section{Results}

Four themes were identified in the data body illustrating what the women were writing about in their blogs: Experiencing frustration, The fear is bigger than death, Preparing for physical changes, and Body and mind are in disharmony All four themes seem to managing emotions from different point of views. These four themes ended up in a concluding main theme; The healing effect of writing a blog (Figure 1).

\section{Experiencing frustration}

There was a frustration in the blog texts, the women felt anger and annoyance since they were unable to do something about their situation. There was also this feeling of disappointment.

The women wrote and repeatedly stated that the health care professional said that they were too young to have breast cancer. Almost everyone writing a blog had the same experience-being assured that their age should in some way protect them from cancer. This made them frustrated, sad and angry, since there was a delay in diagnosis

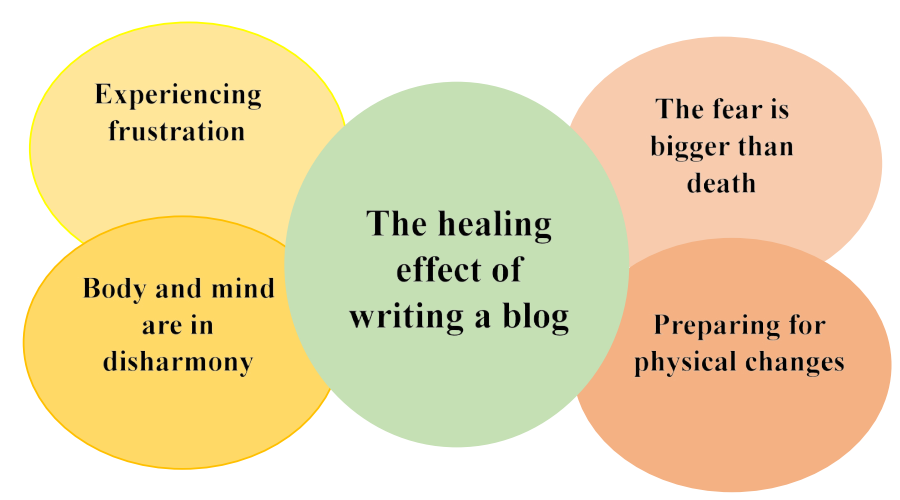

Figure 1. Final thematic map, showing the main theme - the healing effect of writing a blog and its sub-themes

and treatment. There was distrust in the health care system. They were convinced that with an earlier diagnosis, they would have been cured.

There was also frustration and disappointment about being the person who came up with different new treatments or examinations. The medical profession did not inform them or come up with alternative treatment freely. When treatment started, it was frustrating becoming an old woman when you were still young; there were issues about remaining womanly. This frustration followed the women during the cancer trajectory; frustration mixed with distrust.

\section{The fear is bigger than death}

The blog texts presented an unpleasant emotion-fear. Getting the cancer diagnosis was terrifying. They believed that there was nothing but death waiting. However, with the information about the treatment, they tried to focus on that; they wanted to survive.

Since diagnosis day, there had been a constant anxiety. There were worries about the side-effects and there were worries about having relapses. When they had pauses in their treatment cycle, there were worries about how it would affect the disease. There was also fear caused by the delayed diagnosis; how it could affect the outcome.

Some of the woman began treatment too late; they had to accept that despite treatments there was no cure. They had to accept that they would die. These women felt serenity in having planned the funeral. They felt that death could be a liberation for themselves but also for the relatives. Experiencing this fear, living with every day fear and still continuing a kind of everyday life activity was energy-consuming, especially mentally and emotionally.

\section{Preparing for physical changes}

The women wrote about how their bodies changes; the body is the same but not the same. They try to emotional master the situation. In their cancer trajectory, they adapted to their situation and prepared for what would come. There would be some side-effects of the treatment. Losing the hair was very hard, not just because it is a part of the woman's identity but also since it visualizes the disease. Now it was not only that they had cancer, now it also looked like they had cancer. They struggled to keep their hair, but when it started to look awful, wisps of hair falling off, then they prepared for their new look by shaving off the hair. Some made it to their new identity-being bald headed.

Those of them using a wig, asked the hairdresser if they could cut and dye the hair in their natural colour and hairstyle, thus making the wig personal. Even if people noticed it was a wig, they would look roughly the same as usual. 
The body had changed, there was breast asymmetry due to surgery. They had become fat; some body parts were swollen. So, there was a need to modify the clothing.

The women were also prepared for making changes in food intakeknowing that taste sensations would change. Food that they loved before could now became awful. The smell sensation also changed and affected their food intake.

\section{Body and mind in disharmony}

The women wrote about experiencing emotions like a roller coaster. There was lack of harmony between body and mind. This situation created both physical and mental strain. Adversity, tiredness and pain impacted the mind. There was something in the body that they were trying to control, but they had no control at all.

Bodily changes due to premature menopause affected their temper; they became angry easily. They were also more emotionally sensitive, but also angry because of the cancer that had hit them.

There were also feelings of blame; they were at home, treatment was finished but they were so tired and had difficulties to show appreciation; being there with those they loved.

The body was different-ugly-the mind was suspicious; their feelings were in a war zone. Their partners told them that they were loved as the woman they were. But the women were doubtful.

The cancer anxiety monster had found his nest in their body and mind; feeling fragile, crying almost the whole time and having a lot of hard thoughts about what could happen. These feelings came and went and they were never really prepared. There were constant ups and downs; sometimes they felt so peaceful and then angry and disappointed.

\section{The healing effect of writing a blog}

The women's starting point for writing blogs was to set down thoughts, emotions and experiences related to diagnosis, treatment and recovery. There was anxiety, so many worries and fears in these women's minds. Writing a blog was one way to channel these emotions. It was a form of self-help. This writing had a healing effect; it gave them strength to keep on struggling.

Writing blogs was a way to share personal stories and experiences, and thereby support and help other young women who had been hit by breast cancer. The blog could also function as a kind of diary or even testimony-presenting the woman and her life story. Something to be presented to the children in the future.

There was a lack of information to be found about young women and breast cancer. The women read what they could find and then they commented on it in the blog, and the information could be discussed and even validated. These women both read and write blogs as a source for information; giving advice and practical tips.

Writing blogs were providing support to women to strengthening themselves as well as supporting the woman in the same situation. The blogs were also intended to support the families, next of kin or friends. Blogs represented a way of keeping their friends informed and updated. Some women had lost their friends in real life-they just disappeared with the cancer diagnosis. So, these blogs supported them with new friends who were interested in and understood their new situation. Support and confirmation were sent to the bloggers from the people following the blogs.
The healing effect of writing blogs seems clear; the women were supported and confirmed as the women they were-young women with breast cancer. Writing a blog helped the women continue and should be seen as a healing activity.

\section{Discussion}

The main theme in this study was the healing effect of writing a blog, whereas the women used the writing as a channel for emotions and thoughts coming through, but also as a way of sharing experiences. Other studies have also reported about treatment experiences [10,11]. A recent study about expressive writing as an intervention showed similar results, the cancer patients used this writing as a process, writing as a therapeutic activity, and writing as a support to others [13]. The unique thing about the present study is that it focuses on how the women used the blogs and not only on how they presented their side-effects and treatments. In a recently published study [14] a major reason for reading blogs is to search for persons with similar experiences. Understanding the experiences of other cancer patients in a similar situation gave the blog readers and bloggers a feeling of hope and confidence. So, writing blogs may have a healing effect on women themselves as well as others and significant others.

The women reported the feeling of frustration with doctors and with health care system, since they had not paid attention to their situation due to their young age. A breast cancer diagnosis and its treatment interrupt the course of one's life [15], and had brought these women an uncertain future [16]. Many dreams and plans had been interrupted among these young women regarding motherhood or professional fulfilment [4,7]. Similar findings were presented in a study [17], whereas the breast cancer diagnosis caused a great disorganization in the women's lives, bringing them frustration.

In this situation, blogging gave these women the opportunity of sharing their feelings, getting feedback from others who inserted comments and stimuli in the blogs, which supported them with some strength.

It is shown in other studies $[16,18,19]$, that the experience of fear and the phantom of death are constantly present, and this was also reported in the analysed blogs.

It is notable that the fear was more distressing than death: being informed about there was no cure. Fear is about being insecure and living with uncertainty. Not be able to plan and not knowing if there is a future to come [20]. In the present study, the women used the strategy of writing blogs as a way of overcoming the fear and also of helping other women to do the same. When no cure was to be found, the women wrote about acceptance and sorrow, but not in a bitter way. They wrote freely about death and their planning for the funeral, in order to give family, friends and workmates relief. This was also a way to present a memorable picture of themselves as persons.

Body changes due to breast cancer are well known and there are several studies approaching it [16,21-23]. These body changes were also identified by the women writing blogs. In their cancer trajectory they adapted to their situation and prepared for what would come. They realized that their bodies would look different. Their bodies now showed to other people that they had cancer. The women modified clothes, wigs, food etc. so that they would seem quite the same as before. Another way to manage these changes and not hide them or deny them is by sharing feelings as well as videos and photos on the blogs, and being confirmed by others [14]. Thus, they would help others to become gradually familiar with their new body image, and from others' posts and comments they could be encouraged to go on with their lives. 
There is sparse research regarding the effect the treatment of breast cancer has on the women's emotional status, except in regard to depression. The women in this study, wrote about the changed body, how it looked different, but also that the body acted differently. They did not recognize themselves in some ways, which is in agreement with another study [23]. The women experienced their emotions as being in a roller coaster. Similar findings are presented in a study from the relatives' perspective [24], the fear, distress and emotions due to the diagnosis and the treatment. In our study the roller coaster experience seemed to be due to a combination of fear and hormone changes in the body.

The main finding in our study was the healing effect of writing a blog, finding a way to venting their own feelings. Some of the women had never written a blog before and the cancer diagnosis became a reason for doing so, and the blog became a vehicle for this outburst. Blogs were used as a way of exposing aspects of private life, or even intimacies; exposing aspects of everyday life associated with living with a particular disease [25], thereby helping them to cope with the experience. However, this was not the only role of writing blogs. This healing tool also served as a strategy for achieving self-awareness. This means that the process of writing blogs was also a reflexive process through which the women immersed themselves and the things that come close and with which they live. They reviewed life, struggles, plans, and pondered possibilities. This is also pointed out by other studies $[15,26]$. Writing blogs served as a strategy for their own empowerment, and also contributed to the empowerment of other women living in a similar situation.

In addition, the disclosure of personal experiences of breast cancer has contributed much to creating a state of alert for other women with regard to self-care. This was also noticed in another study, whereas internet has become an important source of health information [26]. By gathering knowledge from institutional or medical websites, women become able to establish a new relationship with healthcare professionals and health systems. Despite the problem of trustworthiness, as pointed out in other studies $[27,28]$. there has been an increase in the number of people reading and writing blogs on the breast cancer experience. That means there is also an increase in the number of people who have confidence in these blogs and use their information for the development of self-efficacy.

Writing blogs is an instrument of a younger generation, and their results are positive. Young women are familiar with the language, strategies, varieties and possibilities of blogs. Accustomed to using this instrument, they easily adapt to it when sharing their experiences about breast cancer and can best explore the potential as a healing tool.

Blogs could become a useful tool for healthcare professionals, relatives, patients and people around them. By reading blogs, not necessarily commenting on and writing them, there will be a better and deeper understanding about the effects of a cancer diagnosis. As one study pointed out [29], in these blogs there could be information to assist cancer patients who may not have enough strength for blogging.

Fourteen blogs could be seen as a small sample. The data body contained more than 410000 words in these blogs. It is an amount of data, comparable to more than 100 of interviews. This amount of data is difficult to handle with pure interpretive methods, so the choice of thematic analysis seemed relevant. Thematic analysis is a method that works both to reflect reality and to unravel the surface of reality [12]. Another limitation could be that there are no statements/quotations to facilitate readers understanding. Most qualitative methods use quotations to strengthen their findings. However, following the demand of the Ethical Review Board and protecting the women's' confidentiality, we lean on the systematic analysis we performed and accurate reflections of the content of the entire data set.

\section{Conclusion}

The young women used writing blogs as a healing activity, which is an online health resource and could promote good health. The writing was a channel for emotions and thoughts; a way of sharing experiences. The young women's narratives revealed the impact of the breast cancer experience on their personal, familial and social lives. They expressed frustration about the abrupt interruption of dreams and plans for the future, as well as frustration related to the health system and professionals who did not pay attention to their situation, represent an important alert for all of those who work in this area; breast cancer is no longer a disease of women older than 50 , and young women should be included earlier in the priorities for early detection programs.

Writing and reading blogs with narratives of personal experiences is an important way of supporting women who have/ have had breast cancer. This is an activity that should be included by healthcare professionals and caregivers in order to better understand these women's life situation and needs.

\section{Declarations}

There are no interest of conflict.

Preliminary results from this study was presented at the 7th World Congress on Healthcare and Technologies which were held from September 26-27, 2016 London, U.K.

\section{References}

1. Swedish National Board of Health and Welfare (2013) Cancer Incidence in Sweden www.socialstyrelsen.se.

2. American Cancer Society (2012) Breast Cancer Facts \& Figures 2011 e2012, American Cancer Society, Atlanta, Ga, USA. https://www.cancer.org/content/dam/cancer-org/ research/cancer-facts-and-statistics/breast-cancer-facts-and-figures/breast-cancerfacts-and-figures-2011-2012.pdf

3. Hayes DF (2007) Clinical practice. Follow-up of patients with early breast cancer. $N$ Engl J Med 356: 2505-2513. [Crossref]

4. Avis NE, Crawford S, Manuel J (2005) Quality of life among younger women with breast cancer. J Clin Oncol 23: 3322-3330. [Crossref]

5. Schover LR (1994) Sexuality and body image in younger women with breast cancer. $J$ Natl Cancer Inst Monogr : 177-182. [Crossref]

6. Avis NE, Crawford S, Manuel J (2004) Psychosocial problems among younger women with breast cancer. Psychooncology 13: 295-308. [Crossref]

7. Dunn J, Steginga SK (2000) Young women's experience of breast cancer: Defining young and identifying concerns. Psycho Oncology 9: 137-146. [Crossref]

8. Katz ER, Burwinkle T, Varni JW, Barr RD (2007) Health-related quality of life. In Bleyer WA, Barr RD (eds.) Cancer in adolescents and young adults. Heidelberg, Germany, pp: 387-400.

9. Narimatsu H, Matsumura T, Morita T, Kishi Y, Yuji K, et al. (2008) Detailed analysis of visitors to cancer-related web sites. J Clin Oncol 26: 4219-4223. [Crossref]

10. Sethi SK (2007) Blog/web log - a new easy and interactive website building tool for a non-net savvy radiologist. J Thorac Imaging 22: 115-119. [Crossref]

11. Keim-Malpass J, Baernholdt M, Erickson J, Ropka M, Shroen A, et al. (2013) Blogging Through Cancer: Young Women's Persistent Problems Shared Online. Cancer Nurs 36: 163-172. [Crossref]

12. Braun V, Clarke V (2006) Using thematic analysis in psychology. Qual Res Psychol 3: $77-101$.

13. Gripsrud BH, Brassil KJ, Summers, B, Lode K (2015) Capturing the Experience: Reflections of Women With Breast Cancer Engaged in an Expressive Writing Intervention. Cancer Nurs 39: E51-E60. [Crossref] 
14. Engler J, Adami S, Adam Y, Keller B, Renke T, et al. (2016) Using others' experiences. Cancer patients' expectations and navigation of a website providing narratives on prostate, breast and colorectal cancer. Patient Educ Couns 99: 1325-1332. [Crossref]

15. de Boer M, Slatman J (2014) Blogging and breast cancer: Narrating one's life, body and self on the Internet. Womens Stud Int Forum 44: 17-25.

16. Almeida TG, Comassetto I, Alves KMC, Figueiredo Trezza MCS (2015) Experience of young women with breast cancer and mastectomized. Escola Anna Nery 19: 432-438.

17. Gontijo IBR, Ferreira CB (2014) Feelings of young women facing diagnosis of female breast cancer. Revista Ciência \& Saúde 7: 2-10.

18. Vargens OMC, Bertero CM (2007) Living with breast cancer: how does it affect the life situation and the close relationship of women in Brazil. Cancer Nursing 30: 471-478.

19. Vargens OMC, Bertero CM (2012) The phantom of death improving quality of life: you live until you die. Am J Hosp Palliat Care 29(7): 555-562. [Crossref]

20. Berterö C, Wilmoth Chamberlain M (2007) Breast Cancer Diagnosis and Its Treatment Affecting the Self : A Meta-Synthesis. Cancer Nurs 30: 194-202. [Crossref]

21. Trusson D, Pilnick A (2016) The Role of Hair Loss in Cancer Identity Perceptions of Chemotherapy-Induced Alopecia Among Women Treated for Early-Stage Breast Cancer or Ductal Carcinoma in Situ. Cancer Nurs 39: 1-8E. [Crossref]

22. Paterson CL, Lengacher CA, Donovan KA, Kip KE, Tofthagen CS (2016) Body Image in Younger Breast Cancer Survivors A Systematic Review. Cancer Nurs 39: E39-E58. [Crossref]
23. Klaeson K, Sandell K, Berterö CM (2011) To feel like an outsider: focus group discussions regarding the influence on sexuality caused by breast cancer treatment. Eur J Cancer Care (Engl) 20: 728-737. [Crossref]

24. Saadet Ç, Özgül K (2016) We as Spouses Have Experienced a Real Disaster!: A Qualitative Study of Women With Breast Cancer and Their Spouses. Cancer Nurs 39: E19-E28. [Crossref]

25. Coll-Planas G, Visa M (2016) The wounded blogger: analysis of narratives by women with breast cancer. Sociol Health Illn 38: 884-898. [Crossref]

26. Quinn EM, Corrigan MA, McHugh SM, Murphy D, O'Mullane J, et al. (2013) Who's talking about breast cancer? Analysis of daily breast cancer posts on the internet. Breast 22: 24-27. [Crossref]

27. Wise M, Han JY, Shawb B, McTavish F, Gustafson DH (2008) Effects of using online narrative and didactic information on healthcare participation for breast cancer patients Patient Educ Couns 70: 348-356.

28. Bender JL, Katz J, Ferris LE, Jadad AR (2013) What is the role of online support from the perspective of facilitators of face-to-face support groups? A multi-method study of the use of breast cancer online communities. Patient Educ Couns 93: 472-479. [Crossref]

29. Kim S, Chung DS (2007) Characteristics of cancer blog users. J Med Libr Assoc 95 445-450. [Crossref]

Copyright: $@ 2017$ Vargens OMC. This is an open-access article distributed under the terms of the Creative Commons Attribution License, which permits unrestricted use, distribution, and reproduction in any medium, provided the original author and source are credited. 